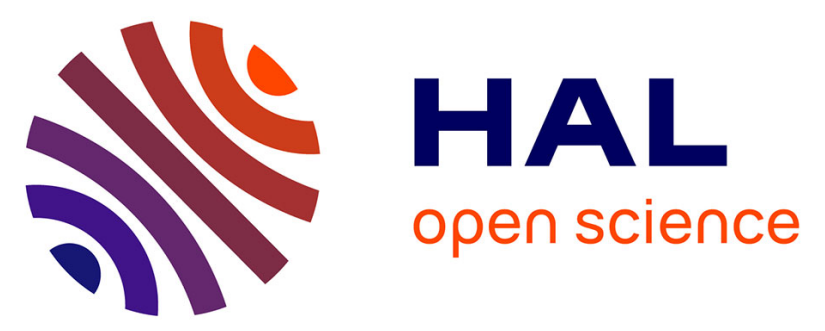

\title{
Options for zonation and grid integration of offshore wind in Vietnam
}

\author{
Phuong H. Nguyen, Dinh Nguyen Van, Hoang Anh Trinh Nguyen, Thi To \\ Nhien Ngo, an Ha Truong, Minh Ha-Duong
}

\section{To cite this version:}

Phuong H. Nguyen, Dinh Nguyen Van, Hoang Anh Trinh Nguyen, Thi To Nhien Ngo, an Ha Truong, et al.. Options for zonation and grid integration of offshore wind in Vietnam. Proceedings of the 2nd Vietnam Symposium on Advances in Offshore Engineering. VSOE2021, 208, pp.509-517, 2022, Lecture Notes in Civil Engineering, 978-981-16-7735-9. 10.1007/978-981-16-7735-9_57 . hal-03080549

\section{HAL Id: hal-03080549 \\ https: / hal-enpc.archives-ouvertes.fr/hal-03080549}

Submitted on 17 Dec 2020

HAL is a multi-disciplinary open access archive for the deposit and dissemination of scientific research documents, whether they are published or not. The documents may come from teaching and research institutions in France or abroad, or from public or private research centers.
L'archive ouverte pluridisciplinaire HAL, est destinée au dépôt et à la diffusion de documents scientifiques de niveau recherche, publiés ou non, émanant des établissements d'enseignement et de recherche français ou étrangers, des laboratoires publics ou privés. 


\title{
Options for zonation and grid integration of offshore wind in Vietnam
}

\author{
Phuong H. Nguyen ${ }^{1,2}$, Van Nguyen Dinh ${ }^{1,3}$, Hoang Anh Nguyen Trinh ${ }^{1}$, To Nhien \\ $\mathrm{Ngo}^{1}$, An Ha Truong ${ }^{1}$ and Minh Ha-Duong ${ }^{1,4}$ \\ ${ }^{1}$ Vietnam Initiative for Energy Transition, Vietnam \\ ${ }^{2}$ TU/e University, The Netherlands \\ ${ }^{3}$ University College Cork, Ireland \\ ${ }^{4}$ Centre International de Recherche sur l'Environnement et le Développement, France
}

\begin{abstract}
With a long coastal line and sea area around 1 million $\mathrm{km}^{2}$, Vietnam has advantages in developing offshore wind power, where several studies have estimated the technical potential up to $475 \mathrm{GW}$ within $200 \mathrm{~km}$ from shore. To contribute to the offshore wind development strategy for Vietnam, this study presents the options for zonation and grid integration to 2030. We identified four potential zones along the coast for offshore wind development by assessing the technical resource areas based on wind speed and variation, ports, synchronous power plants, oil and gas infrastructures, shipping routes, and particular sensitive sea areas. We then investigate the capability to integrate wind capacity regarding the transmission expansion plan in the period 2020 - 2030 by calculating generation adequacy and transmission adequacy. The results specify a possible path for the development of offshore wind which balances out the onshore grid capacity with the quantified capacity from four different wind resource zones. By calculating the loss of load probability with various penetration levels of offshore wind, we find out that $10.5 \mathrm{GW}$ of offshore wind by 2030, spreading across four zones, makes an adequate reliable power supply.
\end{abstract}

Keywords: Offshore wind, zoning, grid integration, Vietnam, wind power, renewable energy.

\section{$1 \quad$ Introduction}

With a long coastline and sea area around 1 million $\mathrm{km}^{2}$ and many zones of favorable wind speeds, Vietnam has a great potential of power source from offshore wind energy $[1,2]$. Along with the high ambition in renewable energy mix scenarios, the technology cost is reducing by years, making offshore wind to be an important source to meet the fast growth rate of energy demand in the country. Several energy mix scenarios in the previous studies $[3,4]$ highlighted also the important role of offshore wind in the energy transition roadmap of Vietnam.

Offshore wind integration plays a crucial role to determine technical boundaries and preliminary economic assessment of integration options [5]. Due to the variability and intermittency of this renewable source, several aspects including the possibility to ensure generation capacity, and stable system operation need to be analyzed thoroughly. At an early stage of the study to investigate offshore wind generation for Vietnam, this preliminary assessment on system adequacy with the given power development plan is necessary to help policy makers sharping a roadmap for the development of offshore wind.

This study aims to explore potential from offshore wind generation in Vietnam to contribute to the sustainable pathway of energy transition in the country. Using the analysis on offshore wind resource zones and the transmission expansion specified in the Power Development Plan 7 Revised (PDPR7) [6] with updates as of the recent document no. 1968/TTr-BCT (2020) [7] and 2491/BCT-DL(2020) [8], this study explores penetration levels of offshore wind capacity while addressing wind integration aspects including generation adequacy and transmission adequacy. A focus will be in the period from now till 2030 to provide an insight on how much offshore wind capacity the grid can accommodate regarding the current development of the infrastructure. 


\section{$2 \quad$ Methods and models}

\subsection{Offshore wind zonation}

Elements for preliminary assessment of strategic zones for offshore wind development are based on the UK methodology [9] and a recent research about potential offshore wind resources in Vietnam [10], which assessed the technical resource areas of offshore wind zones in Vietnam based on wind resource potential and variation, ports, and synchronous power plants. This assessment considers oil and gas infrastructures, shipping routes, and Particularly Sensitive Sea Areas to be excluded from the technical resources areas.

The spatial distribution of the annual mean wind power density at $100 \mathrm{~m}$ height and capacity factor were obtained by using numerical simulations with Weather Research and Forecasting (WRF) model at 10-km resolution for 10 years (2006-2015) and validated with two observational data sets [2]. These observational data sets are (i) wind data observed for 10 years 2006-2015 at six ground-based weather stations located in islands off the coast of Vietnam and run by the Vietnam Center of Hydro-Meteorological Data and (ii) the QuikSCAT (Quick Scatterometer) data. QuikSCAT is the NASA's Earth observation satellite carrying the sea winds scatterometer $[11,12]$. The reference turbine is Vestas V164-8.0 with a rated power of $8 \mathrm{MW}$, a blade length of $80 \mathrm{~m}$, and an approximate hub height of $105 \mathrm{~m}$ [2].

\subsection{Grid integration assessment}

The method used in this national offshore wind integration study refers to the recommended practices from the International Energy Agency (IEA) - Wind expert group [5] with an adaptation to be suitable within the study scope. Since the main focus of the study is about system adequacy with offshore wind integration, load demand will be adopted from the demand scenarios developed from PDPR7, the recent updated directives (428/QD-TTg in 2016, 58/BC-BCT in 2019, and 724/BCT-DL in 2020), as well as other studies like one published by the World Bank [13]. The transmission expansion plan module provides important input for the network model, including mainly 500 and $220 \mathrm{kV}$ transmission lines and substations. The most important module for this study is the offshore wind generation which includes offshore wind capacity fitting into the national energy mix scenarios and associated transmission possibilities to connect to the (nearest) onshore substations.

In order to analyze generation adequacy with various penetration levels of offshore wind, this study developed energy mix models for Vietnam's power system in 2025 and 2030 accordingly, including information reported in PDPR7 and document No.2491/BCT-DL. DIgSILENT PowerFactory is used as the simulation platform that can integrate the energy mix model along with stochastic wind models to analyze the impact of offshore wind uncertainty in terms of Loss of Load Probability (LOLP). With the same simulation platform, this study developed further a network model simulating the current Vietnam's $500 \mathrm{kV}$ and $220 \mathrm{kV}$ grids and its transmission expansion planned in 2025 and 2030 according to PDPR7 and critical update from Document No. 1968/TTr-BCT (2020) and 2491/BCT-DL (2020) to accommodate the high renewable installed capacity recently, i.e. transmission adequacy.

In order to support future integration of offshore wind, this study makes some assumptions for calculations as follow:

- Network models: Integrating a complete $500 \mathrm{kV}$ grid model and some important $220 \mathrm{kV}$ grids.

- Generation models are based on the high generation mix scenario from the PDPR7 with the recent update regarding the commissioning progresses of some important power plants.

- Integrating detailed models of important conventional generators (rating above $600 \mathrm{MW}$ ) and large-scale solar PV and onshore wind installations (rating above 100MW);

- Aggregating smaller renewable resources in provinces to the equivalent models; 
- Simulating offshore wind farms (OWFs) with the standard platform of 600MW for the simulation with various transmission options in different voltage levels, i.e. $220 \mathrm{kV}$ or $500 \mathrm{kV}$, and transmission technologies, i.e. High-Voltage Alternative Current (HVAC) or High-Voltage Direct Current (HVDC).

- Load models: Scaling load demand in the North, Central, and South based on given scenarios developed from PDPR7 with the recent update from MOIT as in Table 1.

- Simulation cases:

- Simulating the "worst case" scenarios only (Pmax scenario at the end of the dry season when the demand of the South at the peak and main hydro power plants in the North is limited their generation);

- Not taking voltage violations as the limit of calculation;

- Not taking contingency study (n-1) into account.

Table 1. Load demand scenarios in regions

\begin{tabular}{llll}
\hline & 2020 & 2025 & 2030 \\
\hline Total peak load demand [MW] & 44,244 & 68,367 & 100,215 \\
Load demand from the North [MW] & 17,698 & 27,347 & 40,086 \\
Load demand from the Central & 4,424 & 6,837 & 10,022 \\
[MW] & & & \\
Load demand from the South [MW] & 22,122 & 34,184 & 50,108 \\
\hline
\end{tabular}

An estimation of the residual capacity of the onshore grid is made to determine which resource zones might be exploited first, as shown in Table 2. The residual capacity is based on the maximum loading of the existing near $500 \mathrm{kV}$ substations to the resource zones and the grid expansion capacity reflected by new planned $500 \mathrm{kV}$ substations in the region. The estimation is based on the thermal rating of the grid assets, i.e. transformer rating, according to the PDPR7. The contingency calculation ( $n-1)$ and stability analysis, which are not taken into account in this study, might lead to lower levels of the residual capacity.

Table 2. Estimation of residual capacity for the onshore transmission to offshore wind resource zones

\begin{tabular}{|c|c|c|c|c|c|c|}
\hline & \multicolumn{2}{|c|}{ Current } & \multicolumn{2}{|c|}{2025} & \multicolumn{2}{|c|}{2030} \\
\hline & $\begin{array}{l}\text { Onshore existing } \\
500 \mathrm{kV} \text { substations }\end{array}$ & $\begin{array}{l}\text { Average } \\
\text { max. loading } \\
{[\%]}\end{array}$ & $\begin{array}{l}\text { New onshore } \\
500 \mathrm{kV} \text { substa- } \\
\text { tions }\end{array}$ & $\begin{array}{l}\text { Residual cap. } \\
\text { [MW] }\end{array}$ & $\begin{array}{l}\text { New onshore } \\
500 \mathrm{kV} \text { substa- } \\
\text { tions }\end{array}$ & $\begin{array}{l}\text { Residual cap. } \\
\text { [MW] }\end{array}$ \\
\hline Zone 1 & $\begin{array}{l}\text { Quang Ninh, Pho } \\
\text { Noi, Dong Anh, } \\
\text { Hiep Hoa, Thuong } \\
\text { Tin }\end{array}$ & 78 & $\begin{array}{l}\text { Bac Giang, Bac } \\
\text { Ninh, Hai Phong }\end{array}$ & 4,032 & $\begin{array}{l}\text { Gia Loc, Long } \\
\text { Bien }\end{array}$ & 5,382 \\
\hline Zone 2 & $\begin{array}{l}\text { Da Nang, Doc Soi, } \\
\text { Thach My }\end{array}$ & 33 & & 3,003 & Binh Dinh & 3,228 \\
\hline Zone 3 & $\begin{array}{l}\text { Song May, Tan } \\
\text { Uyen, Chon Thanh }\end{array}$ & 51 & Long Thanh & 3,335 & $\begin{array}{l}\text { Dong Nai 2, } \\
\text { Binh Duong } 1\end{array}$ & 5,135 \\
\hline Zone 4 & $\begin{array}{l}\text { Cau Bong, Phu } \\
\text { Lam, Nha Be }\end{array}$ & 62 & $\begin{array}{l}\text { Duc Hoa, Long } \\
\text { An }\end{array}$ & 3,743 & $\begin{array}{l}\text { Thot Not, } \mathrm{Cu} \\
\text { Chi }\end{array}$ & 5,318 \\
\hline
\end{tabular}

\section{Result and discussions}

\subsection{Offshore wind zonation}

The Energy Sector Management Assistance Program (ESMAP) [14] estimates the country's total technical potential within $200 \mathrm{~km}$ from the shoreline is $261 \mathrm{GW}$ for fixed wind and $214 \mathrm{GW}$ for floating wind. The offshore wind potential and distribution in ESMAP report agree well with those in [2] that verify the potential of offshore wind in Vietnam.

Based on the potential and variation of offshore wind energy in [2] and [14], and consultations with experts, the offshore wind resource in Vietnam is proposed to be divided into four zones as in Fig. 1 [10]. Zone 1 is the region with the coldest winter 
and consisting of eight provincial sea areas from Quang Ninh to Ha Tinh. In the northern area of this Zone (in the Gulf of Tonkin), there is a sizeable area with a technical potential for fixed foundation wind of $88 \mathrm{GW}$ and an area with a technical potential of $39 \mathrm{GW}$ for floating wind [14]. Zone 2, where the winter is moderately cold, has sea area of seven coastal provinces from Quang Binh to Binh Dinh and marginal potential for offshore wind. Zone 3 is less affected by the winter monsoon and comprising of five provincial seas from Phu Yen to Ba Ria - Vung Tau. Zone 4 is the sea region from Ho Chi Minh city to Kien Giang province, least affected by the winter [10]. Off the coast of Binh Thuan and Ninh Thuan provinces, the mean wind speeds exceed $10 \mathrm{~m} / \mathrm{s}$. This area then extends south and, with average wind speeds falling to $7 \mathrm{~m} / \mathrm{s}$ the area extends up to $125 \mathrm{~km}$ from shore and covers both Zones 3 and 4 . In water depths, less than 50 $\mathrm{m}$, this area alone has technical potential for $165 \mathrm{GW}$ of fixed offshore wind [14]. Outside there is a very large area below 1,000 m water depth and running from the South to the Central region (south of Hue), covering a part of Zone 2, Zone 3 and Zone 4, with a technical potential of $175 \mathrm{GW}$ for floating wind [14].

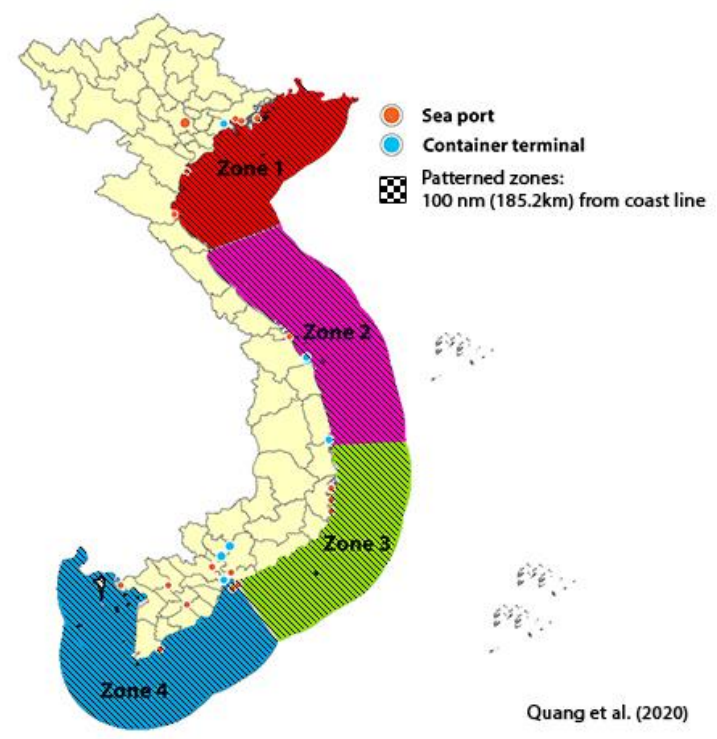

Fig. 1. Location of major ports and container terminals and proposed four zones for evaluation of offshore wind technical resources in Vietnam.

The major seaports and container terminals in Vietnam are mapped in Figure 4, in which the major ports with channel depths greater than $10 \mathrm{~m}$ and maximum vessel size acceptable of 30,000 Dead Weight Tonnage (DWT) all locate in Zone 1, the southern of Zone 2, Zone 3 and Zone 4 [10]. Three container ports in Vietnam: Hai Phong and Dinh Vu in Zone 1, and Tan Cang Sai Gon in Zone 4 are listed in the top 20 of South East Asia [15]. Especially, the Van Phong International Transshipment Terminal is being developed in Van Phong Bay, Khanh Hoa province of Zone 3, which has the depth range of $15-20 \mathrm{~m}$, large area, and expects to accept the maximum vessel size of 9,000 TEUs (Twenty-foot Equivalent Units) or approximately 120,000 DWT. Considering the important information including draft/channel depth, vessel accepted and the available area, the port facilities in Zone 3 are most favorable to offshore wind farm development. Those in Zone 1 and 4 are also in good capacity.

\subsection{Generation adequacy - LOLP}

\section{Stochastic wind models}

This study uses data from the Wind Resource Atlas of Vietnam ${ }^{1}$ to develop the stochastic multi-stage models for onshore and offshore wind generation from different

1 https://globalwindatlas.info/area/Vietnam 
resource zones. The data is used as the input in developing stochastic wind models to calculate the LOLP values. The wind profiles used for the stochastic wind generation models to calculate LOLP include representative wind speed profiles according to three targeting zones for offshore integration. In addition, a typical onshore wind profile is used for onshore wind projects that have been added in the energy mix scenarios in this study.

\section{LOLP calculation}

Within the scope of our study, we took certain assumptions from the PDPR7 and calculate the LOLP values without having complete data (even the historical data for dispatchable generation units is needed to develop the stochastic models). It is assumed that the additional offshore wind capacity aims to cover $10 \%$ of the thermal plant capacity to be added in the corresponding period $2020-2025$ and $2025-2030$. The generation adequacy analysis considers the fixed demand level according to the load scenarios presented in Table 2 for the stochastic assessment. In order to calculate the above LOLP results, a Monte Carlo calculation is conducted, taking the stochastic wind models into account. The wind penetration levels were added to the Vietnam's generation mix in 2025 and 2030 scenarios.

Fig. 2 shows the results of LOLPs according to the increase in offshore wind penetration levels in 2025 and 2030. This study takes the import capacity for the generation mix high case scenario reported in the document No. 2491/BCT-DL as the indication of the expected LOLP value. It was planned that the import capacity is set at the levels of $2,9 \%$ in 2025 and 3,4\% in 2030 accordingly. As it can be seen from the calculation results, a penetration level of above $3 \mathrm{GW}$ offshore wind can secure the $2,9 \%$ level of LOLP in 2025. In order to retain LOLP at the level of 3,4\% in 2030, the offshore wind capacity is expected to be above $10,5 \mathrm{GW}$. In addition, the spatial diversity of wind resource zones would likely have higher effects on securing power supply, i.e. decreasing LOLP levels.
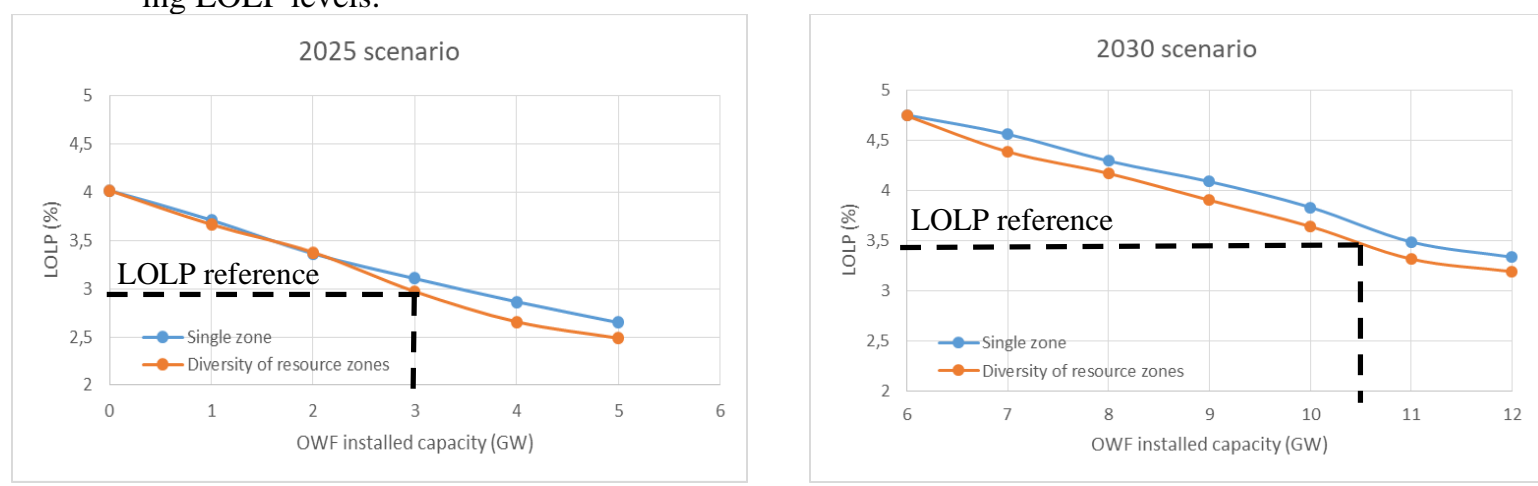

Fig. 2. Impact of offshore wind capacity to the Loss of Load Probability

We find out that $10.5 \mathrm{GW}$ of offshore wind in 2030, spreading across four zones, makes an adequate reliable power source. More precisely, we simulated the Loss of Load Probability to be $3.4 \%$, which compares to the reliability level expected from imported electricity. In order to have a more insight to the wind contribution to power demand adequacy, an extensive measurement-based data crossing the wide geographic areas coupling with available flexibility resources is required [16].

\subsection{Transmission adequacy}

This section takes a step further from the estimation of the onshore transmission residual capacity summarized in Table 2 to calculate possibilities for connecting around 10 GW offshore wind in 2030 as specified in the previous section. Based on the wind resource potential and transmission expansion plan, three main stages for offshore wind integration to reach $10 \mathrm{GW}$ in 2030 are proposed, as follows:

- Integrating the first 100 x 6MW OWF from the southern part of Zone 3 (Binh Thuan sea) by 2023 (see Fig. 3 left frame); 
- Expanding six additional OWFs in the South (mainly Zone 3 and partially Zone 4) by 2025 with the first VSC-HVDC transmission line (see Fig. 3 middle frame);

- Adding ten additional OWFs over the period 2025 - 2030, half of them in the North (Zone 1) connecting via the second VSC-HVDC transmission line. (see Fig. 3 right frame).

\section{System overview with possible OWFs in 2023-2025 period}

Based on the simulation results, it can be concluded that the maximum offshore wind capacity that the grid can absorb is about $4.2 \mathrm{GW}$ till 2025 , coming mainly from Zone 3 and partially Zone 4 . Besides the high potential of wind resources in these zones, the high load demand in the South urges for having higher regional wind penetration. The following Table 4 breaks down the development of OWFs from Zone 3 and 4 with associated transmission technologies each year till 2025.

Fig. 3 left and middle frames show snapshots of electricity flows between main regions in 2023 and 2025. The simulations are calculated with the worst-case scenario during peak periods in April-May when the demand from the South is max while having high production from renewable sources, including offshore wind generation. In 2023, the major part from $3 \mathrm{GW}$ solar PV in Quy Nhon, Ninh Thuan, Binh Thuan together with the first OWF platform $(100 \times 6 \mathrm{MW})$ will be delivered to the central load in the South via 500kV Song May and Tan Uyen substations. Another 1,500 MW flow comes from the Highland areas which have a high amount of small hydropower plants together with renewable sources including solar PV and onshore wind. By 2025, five additional OWF platforms can be added to ensure sufficient power supply for the South and Central areas. A significant surplus of electricity (especially from onshore wind collected from Quang Tri, Ha Tinh, and Nghe An) will be delivered back to the North that approaches the transmission limit.

\section{System overview with possible OWFs in 2025-2030 period}

The calculation shows that about $6 \mathrm{GW}$ capacity of offshore wind can be integrated from mainly Zone 1 ( $3 \mathrm{GW})$ and partially Zone $3(1.2 \mathrm{GW})$ and Zone $4(1.8 \mathrm{GW})$. Table 4 summarizes a possible development plan for OWFs in the period $2025-2030$ in which the capacity distribution in each wind resource zones is specified yearly.

This possible development plan considers the residual transmission capacity of the onshore grids as well as the urgency to meet the peak load demand in the regions concerned. After 2025, the peak load demand in the North will increase and the regional generation capacity will not be sufficient, especially if commissioning new thermal plants is delayed. As can be seen from Fig. 3 right frame, exploiting offshore wind resources from Zone 1 earlier in this period would contribute to reduce the risk of not having generation adequacy for the North and relieve the transmission stress of the Central - North interconnection. Regarding the whole period from 2020 - 2030, a total of $10.2 \mathrm{GW}$ offshore wind capacity can be integrated. 

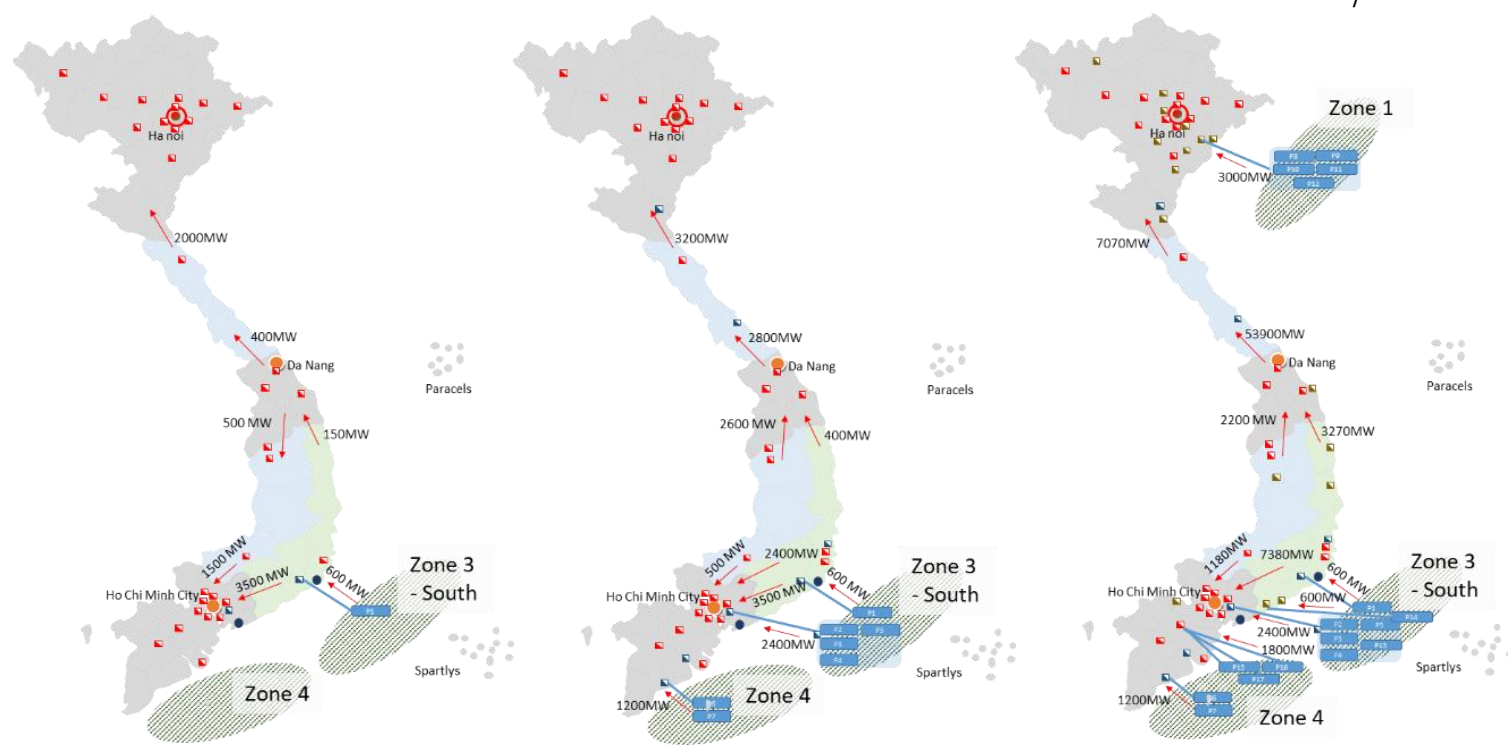

Fig. 3. Load flow snapshot in 2023, 2025 and 2030 (from left to right) - Cases of high renewable sources including max capacity from OWFs.

Table 3. A possible development plan of offshore wind in the period 2023-2025

\begin{tabular}{lllllll}
\hline \multicolumn{2}{l}{ OWF development } & & 2023 & 2024 & 2025 & Total \\
\hline Zone & Platform no. & Trans. Tech. & {$[\mathrm{MW}]$} & {$[\mathrm{MW}]$} & {$[\mathrm{MW}]$} & {$[\mathrm{MW}]$} \\
3 & 1 & $\begin{array}{l}\text { Point-to-point } \\
\text { HVAC }\end{array}$ & 600 & & & 3,000 \\
& 2 & VSC-HVDC & & 600 & & \\
& 3 & & 600 & & \\
& 4 & & & 600 & \\
4 & 5 & Point-to-point & & 600 & & 1,200 \\
& 6 & HVAC & & & & \\
& 7 & Point-to-point & & & 600 & \\
\multicolumn{1}{c}{ Total } & HVAC & $\mathbf{6 0 0}$ & $\mathbf{1 , 8 0 0}$ & $\mathbf{1 , 8 0 0}$ & $\mathbf{4 , 2 0 0}$ \\
\hline
\end{tabular}

Table 4. A possible development plan of offshore wind in the period 2025-2030

\begin{tabular}{|c|c|c|c|c|c|c|c|c|}
\hline \multicolumn{3}{|c|}{ OWF development } & \multirow{2}{*}{$\frac{2026}{[\mathrm{MW}]}$} & \multirow{2}{*}{$\frac{2027}{[\mathrm{MW}]}$} & \multirow{2}{*}{$\frac{2028}{[\mathrm{MW}]}$} & \multirow{2}{*}{$\frac{2029}{[\mathrm{MW}]}$} & \multirow{2}{*}{$\frac{2030}{[\mathrm{MW}]}$} & \multirow{2}{*}{$\frac{\text { Total }}{[\mathrm{MW}]}$} \\
\hline$\overline{\text { Zone }}$ & Platform & Trans. Tech. & & & & & & \\
\hline \multirow[t]{5}{*}{1} & 8 & VSC-HVDC & 600 & & & & & 3,000 \\
\hline & 9 & & & 600 & & & & \\
\hline & 10 & & & & 600 & & & \\
\hline & 11 & & & & & 600 & & \\
\hline & 12 & & & & & & 600 & \\
\hline \multirow[t]{2}{*}{3} & 13 & $\begin{array}{l}\text { Upgrading VSC- } \\
\text { HVDC }\end{array}$ & & 600 & & & & 1,200 \\
\hline & 14 & Point-to-point HVAC & & & & 600 & & \\
\hline \multirow[t]{3}{*}{4} & 15 & VSC-HVDC & 600 & & & & & 1,800 \\
\hline & 16 & & & & 600 & & & \\
\hline & 17 & & & & & & 600 & \\
\hline Total & {$[\mathbf{M W}]$} & & 1,200 & 1,200 & 1,200 & 1,200 & 1,200 & 6,000 \\
\hline
\end{tabular}

\section{Conclusions}

This study explores the options for zonation and grid integration to 2030. Four offshore wind resource zones have been identified with the highest potential in the sea from Phu Yen to Ba Ria - Vung Tau. Some important findings from the grid integration simulations are:

- In the period 2023 - 2025, due to the urgency to meet the peak load demand in the South, this study proposes to develop some first fixed-bottom offshore wind farms 
(OWFs) in Binh Thuan, Ba Ria - Vung Tau, and Bac Lieu sea with the total capacity of $4.2 \mathrm{GW}$.

- In the period 2025 - 2030, the development of OWFs near the coastline in the North with the total capacity of $3 \mathrm{GW}$ can play an important role to relieve inter-region transmission stress. This together with further development of OWFs along with the coastlines of the South Central and the South can make a significant proportion of offshore wind up to $10.2 \mathrm{GW}$.

- We find that $10.5 \mathrm{GW}$ of offshore wind in 2030, spreading across four zones, makes an adequate reliable power source. More precisely, we simulated the Loss of Load Probability (LOLP) to be $3.4 \%$, which compares to the reliability level expected from imported electricity.

This is one of the first wind integration studies for Vietnam, using data from the PDPR7 and some recent updates due to a significant change in the national energy mix recently. More analyses is needed to explore the robustness of alternative infrastructure plan, because this study's result appears sensitive to yet-to-be-decided parameters, such as feed-in-tariffs (FITs) for solar PV and wind. Still, this report confirms that offshore wind can contribute to the energy transition in Vietnam. It is time to start including this technology in Vietnam's power development plans.

\section{References}

1. Sissingh, J., \& Arends, E. (2018). Wind Energy Potential Vietnam.

2. Doan, V. Q. et al. (2019). Usability and Challenges of Offshore Wind Energy in Vietnam Revealed by the Regional Climate Model Simulation. Sola, 15, 113-118. https://doi.org/10.2151/sola.2019-021

3. Hà Dương Minh, Teske, S., Dimitri, P., \& Mentari, P. (2019). Options for wind power in Vietnam by 2030 (p. 23). Vietnam Initiative for Energy Transition.

4. Teske, S., Morris, T., \& Nagrath, K. (2019). Renewable Energy for Viet Nam - A proposal for an economically and environmentally sustainable 8th Power Development Plan for the Viet Nam Government. (p. 113). Australia: Institute for Sustainable Futures (ISF), University of Technology Sydney (UTS).

5. Hannele Holttinen, et al. (2013). Expert Group Report on Recommended Practices: 16. Wind Integration Studies.

6. Prime Minister. (2016). Decision 428/QĐ-TTg - National Power Development Plan for 2011-2020 period (Decision No. 428/QĐ-TTg) (p. 63).

7. Ministry of Industry and Trade. (2020). Letter 1968/TTr-BCT on determining competitive power prices for the development of solar power projects.

8. Ministry of Industry and Trade. (2020). Letter 2491/BCT-DL on the proposal to extend the wind FIT mechanism in Decision 39/2018/QĐ-TTg.

9. The Crown Estate. (2019). Resource and Constraints Assessment for Offshore Wind: Methodology Report (No. 38255- TCE- REP- 024).

10. Quang, V. D. et al. (2020). Evaluation of resource spatial-temporal variation, dataset validity, infrastructures and zones for Vietnam offshore wind energy. Vietnam Journal of Science, Technology and Engineering, 62(1), 3-16. https://doi.org/10.31276/VJSTE.62(1).0316

11. Draper, D. W., \& Long, D. G. (2004). Evaluating the effect of rain on SeaWinds scatterometer measurements. Journal of Geophysical Research: Oceans, 109(C12). https://doi.org/10.1029/2002JC001741

12. Said, F., \& Long, D. G. (2011). Determining Selected Tropical Cyclone Characteristics Using QuikSCAT's Ultra-High Resolution Images. IEEE Journal of Selected Topics in Applied Earth Observations and Remote Sensing, 4(4), 857-869. https://doi.org/10.1109/JSTARS.2011.2138119

13. IES. (2018). Integration of Renewable Energy Targets into Vietnam's Power System - Report for Power System Planning Study to the World Bank Group and Ministry of Industry and Trade.

14. ESMAP. (2019). Going Global: Expanding Offshore Wind to Emerging Markets. Washington DC: World Bank.

15. Dang, V. L., \& Yeo, G. T. (2017). A Competitive Strategic Position Analysis of Major Container Ports in Southeast Asia. The Asian Journal of Shipping and Logistics, 33(1), 19-25. https://doi.org/10.1016/j.ajsl.2017.03.003

Ackermann, T., \& Kuwahata, R. (2011). Lessons learned from international wind integration studies. 